\begin{tabular}{|l|l|l||}
\hline \multicolumn{2}{|c|}{ PublisherInfo } \\
\hline \hline PublisherName & $:$ & BioMed Central \\
\hline \hline PublisherLocation & $:$ & London \\
\hline \hline PublisherImprintName & $:$ & BioMed Central \\
\hline \hline
\end{tabular}

\title{
The MAPK p38 pathway controls TNF synthesis
}

\begin{tabular}{|l|l|l||}
\hline \multicolumn{2}{|c|}{ ArticleInfo } \\
\hline \hline ArticleID & $:$ & 245 \\
\hline \hline ArticleDOI & $:$ & $10.1186 /$ ar-1999-66726 \\
\hline \hline ArticleCitationID & $:$ & 66726 \\
\hline \hline ArticleSequenceNumber & $:$ & 202 \\
\hline \hline ArticleCategory & $:$ & Paper Report \\
\hline \hline ArticleFirstPage & $:$ & 1 \\
\hline \hline ArticleLastPage & $:$ & 3 \\
\hline \hline & $:$ & RegistrationDate : 1999-9-3 \\
ArticleHistory & $:$ & OnlineDate \\
\hline \hline ArticleCopyright & $:$ & Current Science Ltd1999-9-3 \\
\hline \hline ArticleGrants & $:$ & \\
\hline \hline ArticleContext & $:$ & 130753311 \\
\hline \hline
\end{tabular}


Aff1 Kennedy Institute of Rheumatology, London, UK

\section{Keywords}

Knockout, MAPKAPK2, TNF, translation

\section{Context}

The biosynthesis of tumor necrosis factor (TNF) is blocked at the translational level by pyridinyl imidazole compounds such as SB203580, which inhibit the mitogen activated protein kinase (MAPK) p38. MAPK p38 is activated by various pro-inflammatory and "cell-stress" stimuli, and phosphorylates substrates including transcription factors (such as MEF2C) and kinases (such as MAPKAPK2, the subject of this paper). In spite of intense interest in the p38 pathway as a potential target for antiinflammatory therapeutic strategies, little is known about how it regulates TNF synthesis. To generate a mouse knock-out line in order to examine the role of the p38-regulated kinase MAPKAPK2 in the lipopoysaccharide (LPS)-induced synthesis of TNF and other cytokines.

\section{Significant findings}

Homozygous knockout mice also had impaired hsp25 phosphorylation in LPS-treated heart tissue. Compared to wild type, -/- mice showed a significantly improved survival of LPS-induced endotoxic shock (50\% compared to $10 \%$ survival at 24 hours), but no difference in survival after intravenous TNF injection. Spleen cells from MAPKAPK2-deficient mice showed a marked $(>70 \%)$ decrease in LPSinduced production of TNF, interleukin-6 (IL-6) and interferon (IFN) -?. The production of IL-1? and IL-10 was less profoundly affected (30-40\%). Decreases in cytokine production were accompanied by decreases in mRNA in the cases of IL-1? and IL- 6 only. There was no evidence of inhibition of TNF secretion, or of altered TNF mRNA stability in MAPKAPK2-deficient spleen cells. Nor did there appear to be any impairment in germinal centre formation following immunisation, although some evidence for decreased apoptosis in the germinal centres was found by TUNEL (terminal deoxynucleotidyltransferase-mediated dUTP nick end labelling) assay. FACS analysis of spleen or blood cells showed no defect in $\mathrm{CD} 14^{+}, \mathrm{CD}^{+}, \mathrm{CD}^{+}$or $\mathrm{CD} 8^{+}$populations in the MAPKAPK2-deficient mouse (not shown). 


\section{Comments}

This important paper advances our understanding of the control of TNF biosynthesis, providing compelling evidence that regulatory effects of p38 are mediated by its downstream target, MAPKAPK2. A shift in attention from p38 itself to a downstream kinase may ultimately help in the identification of novel anti-inflammatory therapeutic targets. In the light of doubts about the specificity of p38 inhibitors, it is significant that this new evidence is independent of pharmacological inhibition. One reservation concerns the selection of cell populations for some of the assays. For instance the nature of the LPS response in heart tissue is not clear, and more informative experiments might have been done with thioglycollate-elicited or bone-marrow-derived macrophages rather than ill-defined spleen populations. However the MAPKAPK2 knockout line should prove invaluable in addressing several of the intriguing questions raised. For example, is MAPKAPK2 required for the production of TNF in response to stimuli other than LPS, and in disease states such as rheumatoid arthritis? Which of the defects in cytokine production are secondary to the reduction in TNF synthesis, and which are directly caused by loss of MAPKAPK2 activity? In other words what mechanisms of regulation may be shared between TNF and other cytokines?

\section{Methods}

The knockout line was generated by standard methods, involving homologous recombination in embryonic stem cells. Confirmation of the knockout was provided by northern and Southern blotting, and by an in-gel kinase assay for MAPKAPK2. The in vivo phosphorylation of the MAPKAPK2 substrate hsp 25 was also investigated by two-dimensional electrophoresis and western blotting. Survival of wild-type (+/+), homozygous knockout (-/-) and heterozygous (+/-) mice was measured following endotoxic shock or TNF injection. Cytokine production by spleen cells was measured by ELISA, and immune cell populations were analysed by fluorescence-activated cell sorter (FACS) (although the latter data are not shown). Germinal centre architecture was examined by immuno-histochemistry. Northern blots were used to examine the expression of various cytokine-encoding mRNAs, and to examine mRNA stability in actinomycin D chase experiments.

\section{References}

1. Kotlyarov A, Neininger A, Schubert C, Eckert R, Birchmeier C, Volk H-D, Gaestel M: MAPKAP kinase 2 is essential for LPS-induced TNF-a biosynthesis. Nat Cell Biol. 1999, 1: 94-97.

This PDF file was created after publication. 